The International Archives of the Photogrammetry, Remote Sensing and Spatial Information Sciences, Volume XLII-4/W16, 2019 6th International Conference on Geomatics and Geospatial Technology (GGT 2019), 1-3 October 2019, Kuala Lumpur, Malaysia

\title{
EXTENT MAPPING OF A MAJOR FLOODING EVENT ON THE ISLAND OF TRINIDAD USING SPACE-BORNE SYNTHETIC APERTURE RADAR
}

\author{
D. Ramsewak,", B. Maharaj \\ Centre for Maritime and Ocean Studies (CMOS), The University of Trinidad and Tobago, Chaguaramas Campus, Trinidad and \\ Tobago - deanesh.ramsewak@utt.edu.tt
}

KEY WORDS: Flood mapping, GIS, Remote Sensing, Synthetic Aperture Radar (SAR), Trinidad.

\begin{abstract}
:
Flooding events around the world have been increasing both in their occurrence and their intensities within recent decades. Studies have shown that this is most likely linked to climate change effects and anthropogenic activities that lead to pollution. Irrespective of the cause, floods incur massive economic and human losses. Synoptic data on flooding events help to support the planning and management efforts during this disaster event. Remotely sensed data, particularly from satellites is useful for mapping and monitoring large scale flooding events. More specifically, synthetic aperture radar (SAR) allows for data acquisition despite the interference of clouds and other atmospheric elements such as fog, light rain and mist. This study utilized SAR data from the Sentinel-1 satellite to map a major flooding event on the island of Trinidad which occurred during October 18 - 21, 2018. The peak of the flooding was estimated to have occurred on October 20, 2018. The SAR images were first calibrated then geometrically corrected and filtered. A threshold method was then applied to extract the inundated areas. A proprietary algorithm implemented by Geospatial Enabling Technologies (GET) and based on SNAP software, was used for processing Sentinel-1 imagery to separate the open water and non-water (land) areas from the images. Outputs were then integrated into ArcGIS 10.6 mapping software and the extents of the flooded areas were delineated based on the available data. By applying this method to a Sentinel-1 image captured on October 19, 2018 it was revealed that the total flooded area on that date was 9.94 square kilometres. This study provides a brief illustration of the value of SAR data for flood delineation and mapping but also highlights some of the limitations that can be involved when using such technology.
\end{abstract}

\section{INTRODUCTION}

\subsection{Flooding problem}

Floods occur when the water from channels overflows its banks, leading to natural disasters that affect people's livelihood (Ahmad, 2012). According to Kuenzer et al., (2013), more lives are lost due to floods than other natural hazards. It is the most common natural disaster affecting millions globally each year. In recent decades flooding events have increased both in size as well as in occurrence (Berghuijs et al., 2017). Forecasting models have projected that there will be notable increases in flooding along rivers (Winsemius et al., 2016), urban areas (Kundzewicz et al., 2014) and coastal zones (Vitousek et al., 2017). This natural event has been particularly destructive to regions in Asia (Rahman and Thakur, 2017).

Major floods wreaked havoc in India and Japan in mid-2018 (Agarwal, 2018; Masatomo, 2019). Flooding has also become a major natural disaster in Europe lately (Munich Re, 2015), with flooding spanning multiple countries across the continent (De Luca et al., 2017). In the Caribbean region Guyana, Jamaica and Trinidad and Tobago have all recently been impacted by severe flooding events (Reporter, 2019; Rampersad, 2019).

During the period October 18-21, 2018 Trinidad and Tobago (see figure 1) experienced its worst flooding event in 50 years (Matroo, 2019) with the main island of Trinidad withstanding the worst damage. Approximately 150,000 people were affected by the October flooding caused by an Inter-Tropical Convergence Zone (ITCZ) and a tropical wave (Tack, 2019).

The ITCZ, which is a narrow, elongated region of near-surface convergence located near the equator (Siongco et al., 2014), produced widespread cloudiness and precipitation for a sustained period. It is estimated that $80 \%$ of the country was impacted by the rainfall which was an entire months' worth of precipitation in two days (Tack, 2019). Apart from significant agricultural and housing impacts, the flooding crippled the nation's transportation network causing heavy traffic on major highways and roadways (Desk, 2019).

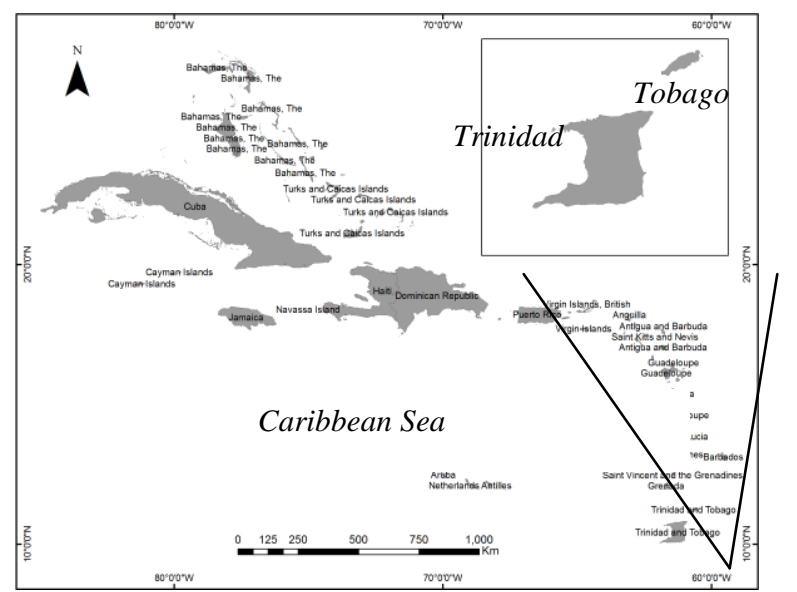

Figure 1. Location of Trinidad and Tobago in the Caribbean.

\subsection{GIS and Remote Sensing}

Flood mapping with GIS and remote sensing has improved due to advancements in geospatial technology and better access to data (Khan et al., 2011). The Multi-Spectral Scanner (MSS) aboard ERTS-1 provided the general public with access to remotely sensed data in the early 1970s allowing for the integration of geospatial data with flood mapping. This was typically carried out using data collected before and after the flooding event (Wang et al., 2002). However, these satellites later referred to as the Landsat 1-8 series (ERTS-1 being later renamed as Landsat-1), had issues with their applicability to flood mapping. 
Optical sensors are often unreliable due to the spectral similarities between burned areas and flooded areas (Pricope, 2012), the lack of available cloud-free images (Biggin and Blyth 1996), and the inability to detect standing water in vegetation (Townsend and Walsh 1998). Aerial remote sensing on the other hand is resistant to extensive clouds and sensor revisit limitations (Colomina and Molina, 2014). Aerial photography has been used effectively for mapping floods, for example in Yuyao, China (Feng et al., 2015). One major drawback with aerial photography however, has been its cost. According to Hess et al., (1990), synthetic aperture radar (SAR) has proven to be a valuable method for detecting flood inundation. SAR sensors detect flooding because flat surfaces scatter the signal away from the sensor, reducing the radiation returned (Gan et al., 2012).

Flooding in vegetated or urban areas can also be detected due to the brightening effects caused by the signal's double-bounce off objects in standing water (Mason et al., 2012). There are several techniques developed using SAR for flood detection including histogram thresholding or clustering (Martinis et al., 2009), radiometric thresholding (Matgen et al., 2011), the application of neural networks in a grid system (Kussul et al., 2008), fractal dimensioning of multi-temporal images (Huang et al. 2011), pixel-based segmentation (Martinis et al., 2009), and statistical active contouring (Horritt et al., 2001)

\section{METHODS AND MATERIALS}

Based on near real-time data, Copernicus Sentinel images generate good information for flood crisis mapping. Sentinel-2 optical imagery has the capability to provide a distinct view of flood extent over a wide area. One major issue with the detection of flooded areas from optical imagery however, is the interference by clouds (Shen et. al., 2019). This problem is exacerbated in tropical regions due to increased levels of cloud cover. An assessment of the Sentinel-2 archives revealed that there were no cloud-free images of Trinidad available during the October 18-21 flooding period that were useful for effectively delineating flooded areas. Figure 2 shows cloud interference in a natural colour composite of the red, green and blue (RGB) bands of a Sentinel-2 image captured on October 21,2018 . Figure 3 shows almost $100 \%$ cloud interference in a natural colour RGB composite of a Landsat- 8 satellite image captured on October 19, 2018. Both of these images illustrate the cloud interference problem present when attempting to use optical imagery for flood mapping in tropical regions.

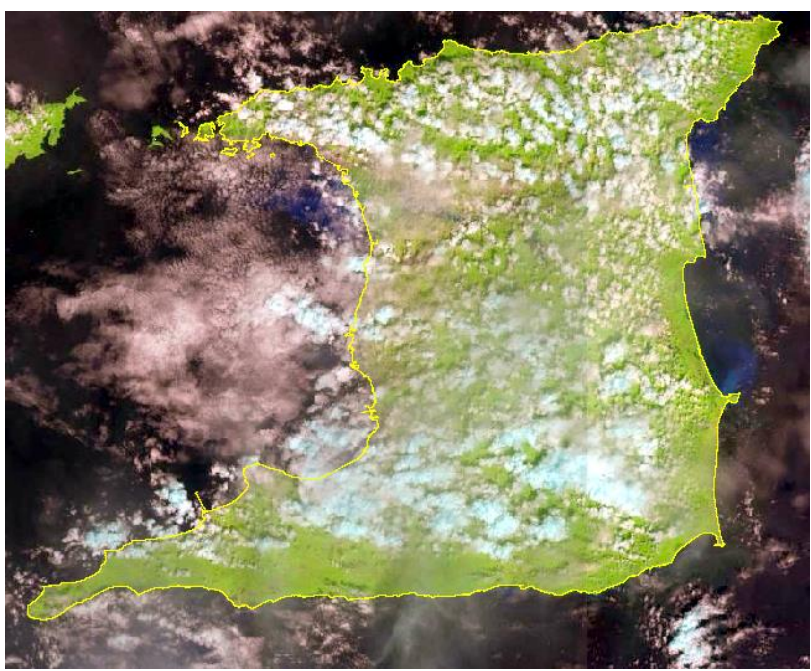

Figure 2. Sentinel-2 RGB image (21-10-18)

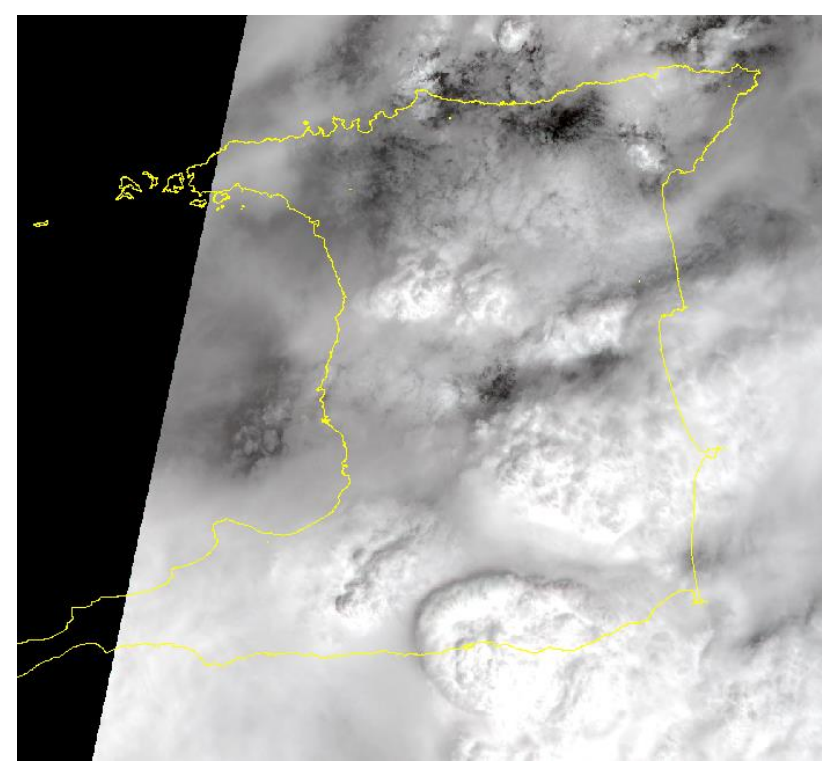

Figure 3. Landsat-8 RGB image (19-10-18)

Sentinel-1 radar imagery is not hampered by clouds and can be used to discriminate between flooded areas, waterlogged areas and dry land. In this study a proprietary algorithm implemented by Geospatial Enabling Technologies (GET) and based on SNAP software, was used for processing Sentinel-1 imagery. This approach was used to detect flooded areas within the study region during October 18-21, 2018. SAR (Ground Range Detected - GRD) images were downloaded from Sentinel Hub, an online satellite data processing engine (Sinergise, 2019). Data from the following dates were acquired:

\section{October 13, 2018 (pre-crisis) \\ October 19, 20182018 (crisis) \\ October 25, 2018 (after-crisis) \\ October 31, 2018 (after-crisis)}

An assessment of the available imagery revealed that there were no SAR images available during the peak of the flooding event on October 20, 2018. The most suitable imagery available was that captured on October 19, 2018 when the flooding had just started.

\section{RESULTS}

After processing the SAR images in SNAP software, the resulting stack for the dates of October 13, 2018 (pre-crisis, red band) and of October 19, 2018 (crisis, green and blue band), which was selected as the most representative combination. The yellow polygon in figure 4 below illustrates the generalized regions that were most heavily impacted by the flooding. The actual flooded regions were derived from the stack of the selected pre-crisis and crisis images by applying a global threshold and are presented below in figure 4 for the northern region of the island of Trinidad. The resulting polygons were then inputted into ArcGIS 10.6 software and the total flooded area for October 19, 2018 was determined to be 9.94 square kilometres. It must be noted that the total extent of the flooding far exceeded this value on October 20, 2018 when it is estimated that the flooding had reached its peak. 


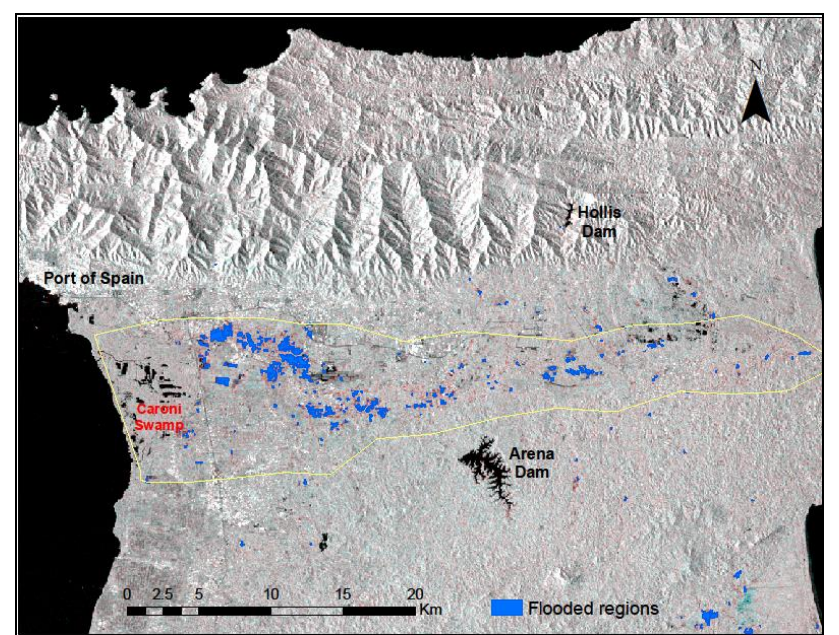

Figure 4. Flooded regions in northern Trinidad delineated in Sentinel-1 SAR imagery

Typically, in SAR imagery, dark pixels occur from low backscatter values and they suggest the presence of water content in the respective areas, as very little energy is reflected back to the radar sensor, due to the smooth water surface (specular reflection). Taking the above into account, after visually inspecting all four images, it was evident that the area receives precipitation during the month of October which occurs during the wet season on the island. The delineation of the flooded regions therefore, was quite a challenging task in this case. Verification of the results of the SAR image processing was conducted based on information derived from drone imagery.

\subsection{CONCLUSION}

This study illustrated the utility in using SAR imagery for mapping flood distribution and extent post a major flooding event on the island of Trinidad in the Caribbean. Also demonstrated were some of the limitations of such technologies as well as the restrictions of optical satellite imagery for flood mapping in tropical regions generally. The peak flood period occurred outside of the capture window of the Sentinel-1 satellite for the island of Trinidad. The revisit time of the satellite therefore proved to be a major limitation in fully exploiting its capabilities for this particular case study. Despite this we find that today's satellites provide higher coverage, frequency and better resolution to solve earth's spatial issues. In this regard we can expect that improvements in satellite revisit frequency and coverage will enhance mapping capabilities even further in the near future.

\section{ACKNOWLEDGEMENTS}

The authors would like to express their thanks to Sinergise's Sentinel Hub (https://www.sentinel-hub.com/) for providing the data for this study and also for the image processing support provided by Geospatial Enabling Technologies (GET) located in Moschato, Athens, Greece (https://www.getmap.eu/).

\section{REFERENCES}

Agarwal, R. (2018). Lesson Learned from Killer Floods in Kerala: Time for Retrospection. Management and Economics Research Journal, 4(2), p.268.
Ahmad Dar, I. (2012). Hydrological Remote Sensing: Journal of Geophysics and Remote Sensing. Journal of Remote Sensing $\&$ GIS, s1.

Berghuijs, W. R., Aalbers, E. E., Larsen, J. R., Trancoso,R. , and Woods, R. A. (2017). Recent changes in extreme floods across multiple continents, Environ. Res. Lett., $12,1-8$

Biggin, D. and Blyth, K. (1996). A Comparison of ERS-1 Satellite Radar and Aerial Photography for River Flood Mapping. Water and Environment Journal, 10(1), pp.59-64.

Colomina, I. and Molina, P. (2014). Unmanned aerial systems for photogrammetry and remote sensing: A review. ISPRS Journal of Photogrammetry and Remote Sensing, 92, pp.79-97.

De Luca, P., Hillier, J. K., Wilby, R. L., Quinn, N. W., and Harrigan, S. (2017), Extreme multi-basin flooding linked with extra-tropical cyclones. Environ. Res. Lett. 12, 114009.

Desk, N. (2019). Uriah Butler Highway still impassable. [online] Guardian.co.tt. Available at: http://www.guardian.co.tt/news/uriah-butler-highway-stillimpassable-6.2.695882.1853d51fb7 [Accessed 12 Feb. 2019].

Feng, Q., Liu, J. and Gong, J. (2015). UAV Remote Sensing for Urban Vegetation Mapping Using Random Forest and Texture Analysis. Remote Sensing, 7(1), pp.1074-1094.

Gan, T., Zunic, F., Kuo, C. and Strobl, T. (2012). Flood mapping of Danube River at Romania using single and multidate ERS2-SAR images. International Journal of Applied Earth Observation and Geoinformation, 18, pp.69-81.

Hess, L., Melack, J. and Simonett, D. (1990). Radar detection of flooding beneath the forest canopy: a review. International Journal of Remote Sensing, 11(7), pp.1313-1325.

Horritt, M., Mason, D. and Luckman, A. (2001). Flood boundary delineation from Synthetic Aperture Radar imagery using a statistical active contour model. International Journal of Remote Sensing, 22(13), pp.2489-2507.

Huang, S., Cai, X., Chen, S. and Liu, D. (2011). Change detection method based on fractal model and wavelet transform for multitemporal SAR images. International Journal of Applied Earth Observation and Geoinformation, 13(6), pp.863-872.

Khan, S., Hong, Y., Wang, J., Yilmaz, K., Gourley, J., Adler, R., Brakenridge, G., Policelli, F., Habib, S. and Irwin, D. (2011). Satellite Remote Sensing and Hydrologic Modeling for Flood Inundation Mapping in Lake Victoria Basin: Implications for Hydrologic Prediction in Ungauged Basins. IEEE Transactions on Geoscience and Remote Sensing, 49(1), pp.85-95.

Kuenzer, C., Guo, H., Huth, J., Leinenkugel, P., Li, X. and Dech, S. (2013). Flood Mapping and Flood Dynamics of the Mekong Delta: ENVISAT-ASAR-WSMBased Time Series Analyses. Remote Sensing, 5(2), pp.687-715.

Kundzewicz, Z. W., Kanae, S., Seneviratne, S. I., Hand-mer, J., Nicholls, N., Peduzzi, P., Mechler, R., Bouwer,. M., Arnell, N., Mach, K., Muir-Wood, R., Braken-ridge, G. R., Kron, W., Benito, G., Honda, Y., Takahashi, K., and Sherstyukov, B.: (2014), Flood risk and 
climate change: Global and regional perspectives, Hydrol. Sci. J., 59 (1), 1-28, doi:10.1080/02626667.2013.857411

Kussul, N., Shelestov, A. and Skakun, S. (2008). Grid system for flood extent extraction from satellite images. Earth Science Informatics, 1(3-4), pp.105-117.

Martinis, S., Twele, A. and Voigt, S. (2009). Towards operational near real-time flood detection using a split-based automatic thresholding procedure on high resolution TerraSARX data. Natural Hazards and Earth System Sciences, 9(2), pp.303-314.

Masatomo, U. (2019). Flood Flows in the Mabi Town District, Kurashiki City, Due to the 2018 West Japan Severe Flood Disaster. E-journal GEO, 14(1), pp.53-59.

Mason, D., Davenport, I., Neal, J., Schumann, G. and Bates, P. (2012). Near Real-Time Flood Detection in Urban and Rural Areas Using High-Resolution Synthetic Aperture Radar Images. IEEE Transactions on Geoscience and Remote Sensing, 50(8), pp.3041-3052.

Matgen, P., Hostache, R., Schumann, G., Pfister, L., Hoffmann, L. and Savenije, H. (2011). Towards an automated SAR-based flood monitoring system: Lessons learned from two case studies. Physics and Chemistry of the Earth, Parts A/B/C, 36(78), pp.241-252.

Matroo, C. (2019). Worst flooding in 50 years. [online] Trinidad and Tobago Newsday. Available at: https://newsday.co.tt/2018/10/21/worst-flooding-in-50-years/

Munichre.com. (2019). [online] Available at: https://www.munichre.com/site/corporate/get/documents_E103 4733363/mr/assetpool.shared/Documents/0_Corporate_Website /Financial_Reports/2016/Annual_Report_2015/30208843_en.pdf [Accessed 26 Feb. 2019]

Pricope, N. (2012). Variable-source flood pulsing in a semiarid transboundary watershed: the Chobe River, Botswana and Namibia. Environmental Monitoring and Assessment, 185(2), pp.1883-1906.

Rahman, M. R., \& Thakur, P. K. (2017). Detecting, mapping and analyzing of flood water propagation using synthetic aperture radar (SAR) satellite data and GIS: a case study from the Kendrapara district of Orissa state of India. Egypt Journal of Remote Sensing and Space Science, 21, S37-S41. https://doi.org/10.1016/j.ejrs.2017.10.002.

Rampersad, S. (2019). Heavy rains bring widespread floods. [online] Guardian.co.tt. Available at: https://www.guardian.co.tt/news/heavy-rains-bring-widespreadfloods-6.2.694382.92f9e5719f [Accessed 26 Feb. 2019].

Reporter, S. (2019). Parts of Georgetown flooded after torrential rainfall - Guyana Chronicle. [online] Guyana Chronicle. Available at: http://guyanachronicle.com/2018/09/14/parts-of-georgetownflooded-after-torrential-rainfall-2 [Accessed 26 Feb. 2019].

Shen, Xinyi, Dacheng Wang, Kebiao Mao, Emmanouil Anagnostou, and Yang Hong. (2019). "Inundation Extent Mapping by Synthetic Aperture Radar: A Review." Remote Sensing 11 (7): 879. https://doi.org/10.3390/rs11070879.
Sinergise, 2019, SENTINEL Hub, Sinergise, Ljubljana, Slovenia, viewed 3 March 2019, < https://www.sentinelhub.com/>.

Siongco, A., Hohenegger, C. and Stevens, B. (2014). The Atlantic ITCZ bias in CMIP5 models. Climate Dynamics, 45(56), pp.1169-1180.

Tack, C. (2019). Thousands affected by freak flood. [online] Trinidad and Tobago Newsday. Available at: https://newsday.co.tt/2018/10/20/thousands-affected-by-freakflood/ [Accessed 12 Feb. 2019].

Townsend, P. and Walsh, S. (1998). Modeling floodplain inundation using an integrated GIS with radar and optical remote sensing. Geomorphology, 21(3-4), pp.295-312.

Vitousek, S., Barnard, P. L., Fletcher, C. H., Frazer, N., Erikson,L., and Storlazzi, C. D. (2017). Doubling of coastal flooding frequency within decades due to sea-level rise Sci. Rep. 71399

Wang, Y., Colby, J. and Mulcahy, K. (2002). An efficient method for mapping flood extent in a coastal floodplain using Landsat TM and DEM data. International Journal of Remote Sensing, 23(18), pp.3681-3696.

Winsemius, H. C., Aerts, J. C. J. H., van Beek, L. P. H., Bierkens,M. F. P., Bouwman, A., Jongman, B., Kwadijk, J. C. J., Ligtvoet,W., Lucas, P. L., van Vuuren, D. P., and Ward, P. J. (2016). Global drivers of future river flood risk, Nat. Clim. Change, 6, 381-385

Revised August 2019 